\title{
LAS COMISARÍAS Y SUBCOMISARÍAS DEL MUNICIPIO DE MÉRIDA: ENTRE LA TRADICIÓN Y LA MODERNIDAD
}

\author{
José A. Lugo Pérez \\ Lizbeth Tzuc Canché \\ Universidad Autónoma de Yucatán, \\ Centro de Investigaciones Regionales, Unidad de Ciencias Sociales
}

Resumen: Las comisarías meridanas son poblaciones rurales en las que sus habitantes, a pesar de estar vinculados al mercado de trabajo urbano del que obtienen la mayor parte de sus ingresos económicos, también conservan ciertos elementos de la economía campesina. Entre estas destaca la práctica de actividades agropecuarias que, en la mayor parte de los casos, son un complemento a las primeras y, en otros, fungen como las principales fuentes de trabajo y de ingresos. Desde esta perspectiva, dichas comisarías, como también otros pueblos de la zona henequenera de Yucatán, ostentan las características de lo que algunos autores han denominado ruralidad o nueva ruralidad.

En este marco nos enfocaremos en la discusión de cómo las creencias y costumbres relacionadas con algunas de las principales prácticas culturales como las ceremonias agrícolas y las fiestas tradicionales, en particular las corridas de toros, han sido impactadas por factores sociales y económicos impuestos por el neoliberalismo económico iniciado en la década de los ochenta.

Palabras clave: tradición, ruralidad, neoliberalismo, prácticas culturales, ceremonias.

AвSTRACT: The comisarias of the municipality of Merida are rural populations in which their inhabitants, despite being linked to the labour market, from which they get most of their income, also hold certain elements of the peasant economy, such as agricultural activities, that, in most cases, work as a complement to the former, and in other cases, act as the main source of work and income. From this perspective, these comisarias, like other towns in the henequen zone in Yucatán, show the features of what some authors have denominate as rurality or new rurality. In this context we will focus on the discussion of how beliefs and customs related to some of the major cultural practices, like agricultural ceremonies and traditional festivals, including bullfights, have been affected by social factors and taxes imposed by the economic neoliberalism that began in the eighties.

KEYwoRDS: tradition, rurality, neoliberalism, cultural practices, ceremonies.

RECEPCIÓN: 11 de octubre del 2010.

ACEPTACIÓN: 9 de noviembre del 2010. 



\title{
LAS COMISARÍAS Y SUBCOMISARÍAS DEL MUNICIPIO DE MÉRIDA: ENTRE LA TRADICIÓN Y LA MODERNIDAD
}

\author{
José A. Lugo Pérez \\ Lizbeth Tzuc Canché \\ Universidad Autónoma de Yucatán, \\ Centro de Investigaciones Regionales, Unidad de Ciencias Sociales
}

\section{Introducción}

El municipio de Mérida, localizado en lo que fuera el corazón de la zona henequenera, está conformado por 11 comisarías y 36 subcomisarías, cuyos habitantes hasta finales de la década de 1970 dependían de los ingresos provenientes de las actividades agropecuarias y principalmente de aquellas relacionadas con el cultivo y producción de henequén. Con la crisis de la industria henequenera en dicha década, que trajo como consecuencia la reducción de las jornadas de trabajo en los planteles, ${ }^{1}$ el Estado puso en marcha el Programa de Reordenación Henequenera y Desarrollo Integral de Yucatán. Su objetivo fue crear fuentes de ocupación, tales como granjas avícolas, ranchos ganaderos, proyectos de fruticultura y horticultura, entre otros para los miles de ejidatarios cuyos ingresos se redujeron al disminuir las jornadas de trabajo en el ejido. Con dicho programa, las comisarías y subcomisarías, las cuales por décadas sólo contaban con los trucs $^{2}$ para comunicarse con la capital del estado, fueron objeto de un amplio programa de construcción de caminos de terracería y carreteras que las comunicarían entre sí y con Mérida. Además, se introdujo el agua potable y la luz eléctrica; esta última no sólo permitiría a los habitantes contar con ese servicio en sus domicilios sino también accionar las bombas de riego de las unidades agropecuarias en fomento (Lugo Pérez y Tzuc Canché, 2006).

A principios de 1980 (y a pesar de los esfuerzos del Estado por crear alternativas de trabajo para los ejidatarios henequeneros), la emigración hacia la ciudad de Mérida, el puerto de Progreso y en menor medida el vecino estado de Quintana Roo comenzó a ser parte fundamental de las estrategias de las unidades domésticas para obtener los ingresos que habían dejado de percibir por su trabajo en los planteles (Lugo Pérez, 2006).

\footnotetext{
${ }^{1}$ En Yucatán así se le denomina a los espacios donde se cultiva henequén.

${ }^{2}$ Carros de tracción animal que se deslizaban por una amplia red de rieles Decauville. Estos carros se utilizaban para llevar las pencas de henequén de los planteles a las plantas desfibradoras y también como medio transporte entre las poblaciones y hasta en los alrededores de la ciudad de Mérida.
} 
Con el inicio de la emigración en la que participaron tanto los padres como los hijos, con o sin derechos ejidales, las actividades agropecuarias empezaron a perder importancia, aunque no se dejaron de llevar a cabo como hasta la actualidad, y con ello se redujeron las extensiones de milpa cultivadas, pasando de tres o cuatro hectáreas ${ }^{3}$ a menos de una, llegando a alcanzar hasta los cuatro o cinco mecates. ${ }^{4}$ Esto significa que la producción obtenida en las milpas no era suficiente para la reproducción económica de las unidades domésticas, razón por la que éstas comenzaron a depender en mayor medida de los ingresos obtenidos en el mercado de trabajo urbano, en el sector secundario y terciario.

En este sentido, se está hablando de poblaciones rurales en las que sus habitantes (a pesar de estar vinculados al mercado de trabajo urbano del que obtienen la mayor parte los ingresos económicos) también conservan ciertos elementos de la economía campesina, como lo es la práctica de actividades agropecuarias. Estas últimas en la mayor parte de los casos son un complemento a las labores urbanas y, en otros, fungen como las principales fuentes de trabajo y de ingresos. Desde esta perspectiva, las comisarías del municipio de Mérida, como también otros pueblos de la zona henequenera de Yucatán, presentan las características de lo que algunos autores han denominado como rurbalidad o nueva ruralidad (Cruz Rodríguez, 2002). Esto significa que no son propiamente rurales ni urbanas, en el entendido que sus habitantes se abocan a actividades agropecuarias y también se vinculan al mercado de trabajo urbano, de donde obtienen la mayor parte de sus recursos económicos.

En el marco de la rurbalidad nos enfocaremos en la discusión de cómo este proceso ha impactado en las creencias y costumbres relacionadas con algunas de las principales prácticas culturales como las ceremonias agrícolas y las fiestas tradicionales en honor a los santos patronos, en particular la organización de las corridas de toros. Es decir, trataremos de explicar cuáles son los factores sociales, económicos y religiosos que han incidido en los cambios y transformaciones de los elementos culturales antes expuestos. Ello nos permitirá comprender cómo han sido y cómo se han adecuado dichos elementos a las nuevas condiciones impuestas por la estructura económica, marcada por el neoliberalismo económico desarrollado a principios de la década de los ochenta. Si bien en este trabajo nos abocamos principalmente a las comisarías meridanas de Komchén y San José Tzal, localizadas a $21 \mathrm{~km}$ de Mérida, también haremos referencia a otros pueblos de la zona henequenera como Samahil, Tetiz y Eknakán, los dos primeros distantes a $32 \mathrm{~km}$ y el tercero a $55 \mathrm{~km}$ aproximadamente de la capital. El objetivo es mostrar cómo lo que sucede en poblaciones relativamente cercanas no es muy diferente a lo que acontece en otras mucho más alejadas.

\footnotetext{
${ }^{3}$ Una hectárea equivale a 25 mecates.

${ }^{4}$ Un mecate equivale a 400 metros cuadrados.
} 


\section{Algunas características culturales de las poblaciones de estudio}

Las comisarías de Komchén y San José Tzal, la primera localizada al norte y la segunda al sur de Mérida, son poblaciones que a pesar de la cercanía con la capital y la dependencia de sus pobladores con el mercado de trabajo urbano, conservan ciertos elementos culturales que caracterizan a la sociedad rural, mientras que otras comunidades están siendo desplazadas por el impacto de la influencia urbana. Por principio, se puede afirmar que sus pobladores son de descendencia maya y esto queda de manifiesto en los apellidos de los integrantes de las familias, donde predominan los de origen maya; en segundo lugar están aquellos con uno maya y el otro español y, en menor medida, existen individuos con ambos de origen español (Padrón Municipal de Mérida, 1992-1994).

A pesar de la creciente vinculación de sus pobladores con el mercado de trabajo y la influencia de los elementos culturales urbanos, la lengua maya continúa fungiendo como medio de comunicación al interior de las comisarías y subcomisarías, sobre todo en el ámbito doméstico, en las tiendas y en las conversaciones entre amigos. La lengua maya no es sólo propia de los adultos sino también de los jóvenes, e inclusive de los niños, quienes a pesar de que muchas veces afirman no hablarla o sólo entenderla, la emplean para comunicarse con los demás integrantes de su familia y con sus amigos (Tec Chan, 2005). A este respecto, en un foro realizado en la ciudad de Mérida se abordó, entre otras cosas, que la pena y la discriminación están provocando la disminución del número de niños hablantes de la lengua maya (Diario de Yucatán, mayo del 2009: 12).

Otro de los elementos culturales distintivo de la sociedad rural maya, sin lugar a dudas, lo constituye el huipil de la mujer yucateca. Esta prenda está perdiendo terreno ante el avance del vestido occidental, lo que es evidente al observar cómo las jóvenes de estas comisarías meridanas han dejado de portarlo como vestimenta de uso diario, relegándolo sólo para eventos especiales como las vaquerías realizadas en honor de los santos patronos. La vaquería es el baile con el que se da inicio a las festividades del santo patrono; entonces las mujeres portan sus ternos multicolores, sus alhajas de filigrana originalmente de oro (y en la actualidad de fantasía), zapatos altos de color blanco, el pelo adornado con un lazo y con flores. Los hombres, por su parte, llevan pantalón blanco, filipina y sombrero del mismo color, alpargatas chillonas (xanakehueles) y un paliacate rojo en la bolsa delantera del pantalón. A las vaquerías, en las que se baila únicamente jaranas interpretadas por las charangas jaraneras, acuden delegaciones de adultos, jóvenes y niños, procedentes de las comisarías y subcomisarías vecinas, ya sea aquellas alcanzadas por la mancha urbana como las más alejadas de la ciudad de Mérida. Estos bailes regionales se desarrollan generalmente en los corredores de los palacios municipales o inclusive en las canchas de basquetbol, dependiendo de la afluencia de bailadores (figura 1).

En la vida cotidiana el huipil está siendo desplazado por el vestido occidental. Es posible observar esto entre las mujeres jóvenes, empleadas de las plantas ma- 


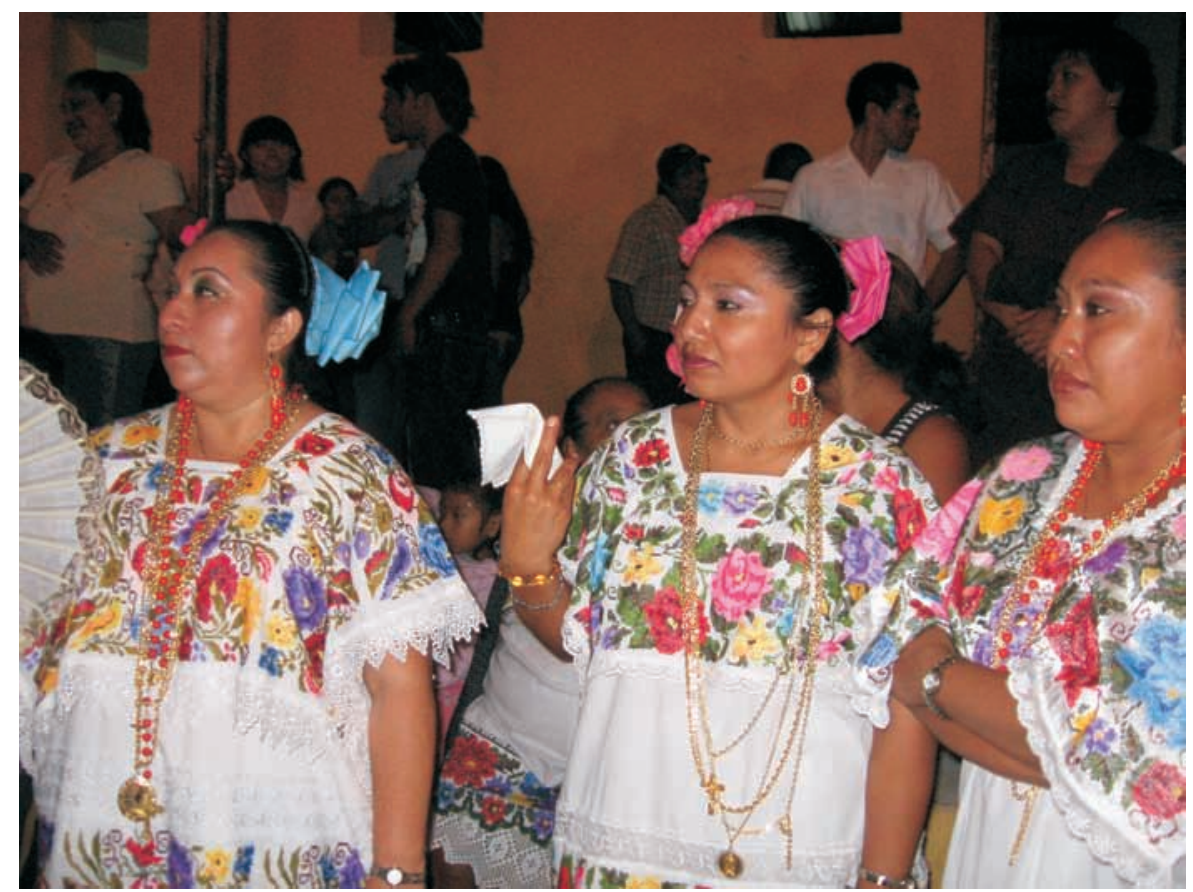

Figura 1. Mestizas con terno de gala en la vaquería. Foto de los autores

quiladoras, de comercios o entre aquellas que trabajan en el servicio doméstico en la ciudad de Mérida. El abandono de la vestimenta tradicional podría explicarse como resultado de la influencia de la cultura urbana y, al mismo tiempo, como una estrategia de las mujeres para no ser discriminadas (tal como sucede con los hablantes de la lengua maya) en la sociedad urbana a la que acuden necesariamente en busca de trabajo. Otro elemento que influye en el abandono del huipil es su costo de aproximadamente \$ 600, el cual rebasa en mucho al de un vestido occidental de uso diario.

Otros elementos culturales característicos de la sociedad rural maya, los yerbateros y las comadronas, que tenían presencia en las comisarías y subcomisarías meridanas, están en franca decadencia. En las subcomisarías del sur se sabe de algunos yerbateros aún ejerciendo y a quienes acuden personas, inclusive de la ciudad de Mérida, en busca de alguna pócima para curar una enfermedad física o espiritual; en las del norte se sabe que al menos en dos de ellas, incluyendo a Komchén, hay dos, uno de ellos muy joven. En lo que respecta a las comadronas, su participación en la atención de partos ha dejado de ser prioritaria, quizás porque en las comisarías de estudio se cuenta con clínicas del Seguro Social o de la Secretaría de Salud e inclusive médicos particulares. Las mujeres embarazadas prefieren acudir a las clínicas locales o trasladarse para su atención al hospital Agustín O’Horán de la ciudad de Mérida. 
Algunos ritos de paso como el hetzmek ${ }^{5}$ y de consagración de los espacios de trabajo (Fernández Ruz, 2005: 60) continúan llevándose a cabo en algunas comisarías y subcomisarías, mismos que son motivos de fiestas en las que se preparan alimentos que son repartidos entre los familiares e invitados.

Sin lugar a dudas, en las comisarías y subcomisarías meridanas se continúan reproduciendo algunas prácticas propias de la cultura maya mientras otras están en franco desuso o se están adecuando a las nuevas condiciones impuestas por la influencia urbana que se transmite a través de los medios de comunicación masivos, la vinculación de los pobladores al mercado de trabajo urbano y más recientemente, desde la década de los ochenta, la creciente inmigración de familias procedentes de la ciudad de Mérida, de otros municipios de Yucatán e inclusive de otros estados de la República Mexicana. Dicha inmigración se ha recrudecido, sobre todo a principios de la década de los noventa, con el Programa de Certificación de Derechos Ejidales (Procede) que permite a los ex ejidatarios vender sus terrenos parcelados, situación que ha favorecido a las empresas constructoras y a los particulares para adquirir grandes extensiones de tierra que destinan de manera prioritaria a la construcción de fraccionamientos y residencias. Un ejemplo de este hecho es el desarrollo residencial llamado Country Club, localizado al norte de Mérida, que cuenta, entre otros muchos servicios, con una zona residencial y campo de golf.

\section{La milpa y las ceremonias agrícolas en Komchén y San José Tzal}

Con base en diversas investigaciones llevadas a cabo en pueblos de la zona henequenera, se puede plantear que las ceremonias agrícolas están en franco abandono como resultado de varios factores como la práctica de cultos religiosos diferentes al católico, la falta o desaparición de los h-menoob (sacerdotes mayas), la escasez de montes altos (yaaxché), pero principalmente por la pérdida de importancia de la actividad milpera como medio para la obtención del grano destinado a la alimentación familiar y a la cría de animales domésticos. Este último fenómeno se manifiesta en la reducida extensión de terrenos destinados a esta actividad y por la necesidad de los ex ejidatarios henequeneros de vincularse al mercado de trabajo como una de las principales estrategias para la reproducción de sus unidades domésticas.

\footnotetext{
${ }^{5}$ Ceremonia en la que a los niños y niñas de menos de un año de nacidos, colocados a horcajadas en las caderas de sus padrinos, se les dice una serie de letanías mientras les dan siete vueltas alrededor de una mesa. También les dan de comer pepita molida y huevo duro, les ponen en las manos diversos objetos relacionados primeramente con las actividades del campo y de la cocina, dependiendo del género, y artículos escolares, como cuadernos o lápices. Todo ello con el objetivo de que sean personas inteligentes, trabajadoras, responsables y de bien.

N. del E.: sobre el hetzmek, también se puede consultar el volumen XXXIII de Estudios de Cultura Maya: 93-103.
} 
A mediados de la década de los noventa se llevó a cabo una investigación en Samahil para estudiar el impacto del programa citrícola, ${ }^{6}$ implementado por el Estado, para subsanar los estragos de la crisis henequenera entre los ex ejidatarios. Como parte de esa investigación se obtuvo información adicional que se utilizó para la elaboración del trabajo: "Las ceremonias agrícolas y su paulatino abandono en Samahil, Yucatán", donde damos cuenta de cómo los factores religiosos, culturales, sociales y económicos han incidido en la pérdida de importancia de las ceremonias agrícolas tradicionales. Allí también se pudo constatar que no sólo ha disminuido el número de practicantes de dichos ritos, sino que también quienes las llevan a cabo las han adecuado a las nuevas condiciones impuestas por la estructura económica prevaleciente (Lugo Pérez y Tzuc Canché, 2002). Por ejemplo, la reducción de las extensiones cultivadas y la consecuente disminución del monto de las cosechas han favorecido que las ceremonias que antes se efectuaban en las sementeras ahora se realicen en altares domésticos en los que se ofrendan los productos obtenidos de las milpas.

En los casos de la hacienda Eknakán y el pueblo de Tetiz, ${ }^{7}$ de un total de 53 agricultores entrevistados en ambas localidades se encontró que $72.6 \%$ de la muestra afirmó no realizar las ceremonias agrícolas, aunque sí tenía conocimientos de ellas porque sus padres o ellos mismos las habían efectuado en un momento dado; mientras que 12.9 \% las continúan realizando, ya sea en la milpa o bien en los altares domésticos. De igual manera, únicamente $4.8 \%$ de la muestra total manifestó que lleva a cabo alguna ceremonia pecuaria, tanto para los cuidadores del ganado (Wan Thul) como para pedir a Dios que no se enfermen y mueran sus aves de corral.

Esta información obtenida en poblaciones ex henequeneras, unas localizadas relativamente cerca de Mérida, como lo es Samahil, y otras más alejadas como Tetiz y Eknakán, nos permite saber que las ceremonias agropecuarias están en proceso de abandono por el reducido número de agricultores que las continúan efectuando. También nos señala que los pocos practicantes las están reelaborando, es decir, a pesar de la creciente dependencia de éstos con respecto al mercado de trabajo urbano y de la influencia externa, dichas ceremonias se resisten a ser olvidadas. En estos trabajos se observó cómo entre los practicantes de las ceremonias agrícolas, el número de agricultores que las realizan en los terrenos destinados a las milpas se reduce mientras el de quienes las efectúan

${ }^{6}$ En Samahil, la citricultura se inició a principios de la década de los setenta con apoyo del Instituto Nacional Indigenista (INI) y fue abandonada años después. A principios de la década de los ochenta, la citricultura fue retomada pero esta vez como parte del ya mencionado Programa de Reordenación Henequenera y Desarrollo Integral de Yucatán.

${ }^{7}$ La información de estas poblaciones se obtuvo del trabajo de campo realizado durante el 2008 como parte del proyecto de investigación multidisciplinario "Prevención de la enfermedad de Chagas y otras zoonosis transmitidas por vector, a través de la participación comunitaria, en poblaciones rurales del estado de Yucatán", en el que participamos investigadores de la Unidad de Biomédicas y de Sociales del Centro de Investigaciones Regionales "Dr. Hideyo Noguchi” y la Facultad de Medicina de la Universidad Autónoma de Yucatán y coordinado por el doctor Mario Barrera. 
en los altares domésticos se incrementa. Con base en lo expuesto, discutiremos la información obtenida en las comisarías meridanas de estudio, donde se puede observar que las características ya descritas en las otras poblaciones de la zona henequenera, mucho más alejadas de la capital del estado, no difieren mucho de lo que sucede en el medio rural de la zona metropolitana.

En Komchén de un total de 19 milperos mayores de 60 años, que además llevan a cabo otras actividades agrícolas, $10.52 \%$, afirmó realizar alguna ceremonia, mientras que $89.47 \%$ dijo que desde hace algunos años las dejaron de practicar. Por su parte, en la comisaría de San José Tzal, de un total de 19 productores del mismo rango de edad anterior, 60 años, 57.89 \% confirmó que realiza algún tipo de ceremonia relacionada con la agricultura, ya sea en la sementera o en los altares domésticos. Como se puede observar, en esta última comisaría, localizada al sur de Mérida, hay un mayor número de agricultores que continúan realizando alguna ceremonia en agradecimiento a los beneficios recibidos a través de la milpa.

Los agricultores manifestaron diversas razones por las que consideran que las ceremonias han perdido presencia. Una de las principales se refiere, sin duda, a la reducción de las extensiones dedicadas a la milpa que si bien en décadas anteriores alcanzaban entre 3 y 4 hectáreas, en la actualidad, en el mayor porcentaje de los casos, sólo llegan a tener entre 3 y 10 mecates, y únicamente en siete casos se eleva a 1 hectárea. Sólo un agricultor manifestó cultivar 2 hectáreas. Esto significa que $78.94 \%$ de los 38 agricultores de ambas comisarías obtuvieron una producción milpera reducida, sólo para cubrir las necesidades de las familias para unos pocos meses del año. Por tanto, no hay un excedente que permita destinarlo a la preparación de los alimentos que tradicionalmente se deben ofrecer a los dueños del monte y a Dios, tanto durante la preparación del monte para la siembra como para dar gracias por la cosecha obtenida.

Otras de las razones que argumentan los productores para no llevar a cabo las ceremonias agrícolas es la carencia de montes altos, aquellos que nunca se han utilizado para la siembra de milpas o que han permanecido en descanso por más de 15 años y ello ha permitido su regeneración. Para los agricultores sólo estos tipos de montes requerirían de la realización de las ceremonias para solicitar permiso a sus dueños y a Dios para la tumba, quema, siembra y cosecha. En la medida que en la actualidad la mayor parte de los montes destinados para la siembra de las sementeras y otros cultivos son de los denominados xlapaches, lo que significa que han sido usados con regularidad, no requieren que se les ofrezcan las ceremonias agrícolas porque, a decir de los productores, están acostumbrados a que se trabaje en ellos. De realizarlas también se tendrían que repetir en los años venideros cada vez que se cultiven. En otras palabras, se acostumbraría de nuevo a los dueños del monte a las ceremonias agrícolas y, en caso de no llevarlas a cabo, provocaría enfermedades a los milperos como calenturas, dolores de cabeza y otros padecimientos físicos.

Los milperos también argumentaron que los h-menoob, sacerdotes mayas responsables de realizar las ceremonias, no se encuentran en las poblaciones cir- 
cunvecinas sino que hay que viajar a otros municipios para hallarlos. En las comisarías y subcomisarías de Mérida, según comentaron los entrevistados, los h-menoob que se encargaban de las ceremonias ya han fallecido y al parecer sus conocimientos no han sido transmitidos a las nuevas generaciones para continuar con esta tradición. Esto ha contribuido a que los milperos adopten nuevas formar de agradecer a los dioses por las cosechas obtenidas.

La pertenencia a religiones ajenas a la católica también es causa de que los milperos abandonen las ceremonias agrícolas, tal como se observó en el pueblo de Samahil. En el caso de las comisarías de Mérida, de los 36 productores entrevistados sólo uno pertenece a una religión cristiana que le impide realizar algún tipo de ceremonia en el espacio destinado a la milpa, pues él ha dejado de creer en los dueños del monte.

Entre los productores que hacen alguna ceremonia relacionada con la agricultura se pueden encontrar básicamente tres tipos: los que las continúan efectuando en los espacios destinados a las milpas, los que las realizan en sus propias casas, en los altares domésticos (figura 2) y, por último, los que las practican en sus templos cristianos o en las iglesias católicas. Los productores que corresponden al primer tipo están conscientes de que antes de proceder a la quema del espacio destinado a la milpa es conveniente ofrecer oraciones para solicitar el permiso a los dueños del monte y a Dios por utilizar ese espacio. También lo hacen para pedirles perdón porque al proceder a la quema muchos animales e insectos que ahí habitan, sin causarle daños al ser humano y que están bajo su resguardo, van a morir calcinados. De esta manera, esperan que los dueños del monte les permitan trabajar la tierra sin tener accidentes y además obtener una buena cosecha para la alimentación de su familia.

Antes de proceder a la siembra, los milperos hacen oraciones y ofrecen saká ${ }^{8}$ en los cuatro puntos cardinales y en el centro de la sementera. Posteriormente, antes de la cosecha los milperos seleccionan las mejores mazorcas para preparar con ellas las ofrendas como el saká, el sakol ${ }^{9}$ y los pibinales ${ }^{10}$ que posteriormente ofrecerán, junto con sus oraciones, como muestra de agradecimiento por el grano obtenido y también a manera de permiso para bajar los elotes. En caso de que la ceremonia no se lleve a cabo se cree que el productor o algún miembro de su familia pueden enfermar. Esta creencia está documentada en el trabajo realizado en Samahil (Lugo Pérez y Tzuc Canché, 2002). Un dato que conviene destacar es el hecho de que las ceremonias agrícolas son realizadas principalmente por los productores que siembran una o más hectáreas. Esto presupone que son las personas que cuentan con mayor poder económico y que por ello pueden destinar recursos al pago de jornaleros para realizar los trabajos del campo; dichos

\footnotetext{
${ }^{8}$ Bebida preparada con maíz y endulzada con miel de abeja o azúcar.

${ }^{9}$ El sakol es una especie de atole hecho de maíz al que se le agrega trozos de masa rellena con carne de puerco o de ave previamente cocida bajo tierra y condimentada con achiote.

${ }^{10}$ Los pibinales son mazorcas de maíz cocidas bajo tierra.
} 


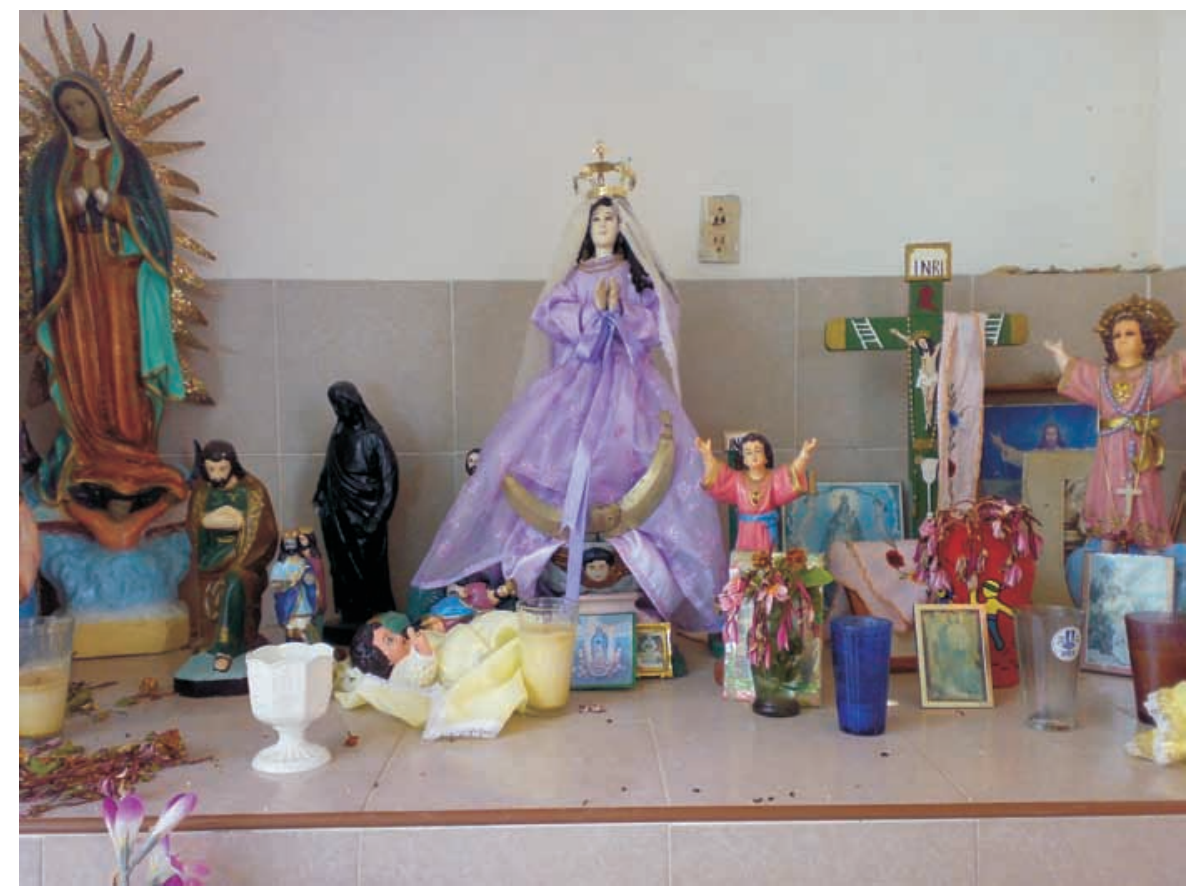

Figura 2. Altar doméstico. Foto de los autores

factores redundan en una mayor cosecha y en la posibilidad de utilizar parte de ella en la preparación de los alimentos que se ofrecen a los dioses.

Sin embargo, hoy en día la ceremonia más común relacionada con la milpa, sin lugar a dudas, es la que se realiza en los hogares y de manera específica en los altares domésticos. El mayor porcentaje de los milperos entrevistados, que son los que cultivan mucho menos de una hectárea, afirmó que después de levantar la cosecha preparan pozole, elotes salcochados, pibinales y atole, entre otros alimentos, y se ofrecen en los altares como una forma de agradecimiento a Dios por los bienes recibidos. Además, se realizan oraciones en los que la rezadora nombra a los jóvenes que continuarán con esta tradición de agradecer por los productos de la cosecha; ellos, a su vez, se comprometen a realizar estas ofrendas a sabiendas que de no cumplir corren el riesgo de contraer alguna enfermedad.

Por último, como ya se mencionó, están los productores que llevan sus ofrendas a las iglesias donde regularmente asisten, protestante o católica, que consisten, al igual que en los casos anteriores, en atole, elotes y otros productos derivados del maíz.

Como se ha visto, son varios los factores que han contribuido a que las ceremonias relacionadas con la agricultura, y de manera específica con la milpa, estén cayendo en el abandono en estas dos comisarías. Dicha situación, sin lugar 
a dudas, se puede generalizar en la mayoría de las restantes 45 que integran el municipio de Mérida, tal como se ha podido observar en los otros pueblos de la zona henequenera mucho más alejados y ya señalados líneas arriba.

\section{Las fiestas en honor a los santos patronos}

Las fiestas patronales, legado de la cultura española, se encuentran diseminadas a lo largo y ancho del territorio nacional, tanto en el medio urbano como en el rural, aunque su práctica conlleva características particulares de acuerdo con la región y grupo étnico de que se trate. En Mérida las fiestas patronales más conocidas son las que se realizan en honor de Santiago Apóstol, la Virgen de la Asunción y el Cristo de las Ampollas; la primera se realiza en el barrio de Santiago, la segunda en la colonia Chuburná de Hidalgo y la tercera en la Catedral. Para mayor información sobre los gremios y las fiestas patronales se puede consultar la obra Izamal festivo (Fernández Repetto y Negroe Sierra: 2006). Las corridas de toros, como parte de las fiestas patronales, se realizan principalmente en los pueblos y en algunas de las ciudades más importantes como Tizimin e Izamal, entre otras. Para mayor información sobre este tema se cuenta con el trabajo del etnomusicólogo Max Jardow-Pedersen llevado a cabo en poblaciones del oriente de Yucatán, donde analiza, entre otros muchos aspectos, el significado de las corridas de las fiestas patronales y su relación con la cosmovisión maya (JardowPedersen, 1981). Lo importante de dicho trabajo es que nos muestra la manera tradicional en que se organizan y desarrollan estas fiestas con los elementos culturales que han permanecido al margen de la influencia externa.

En este apartado, por el contrario, nos abocaremos a destacar, al igual que como lo hemos hecho con las ceremonias agrícolas, algunos elementos culturales relacionados con las fiestas patronales que han permanecido y también cuáles se están transformado como resultado de la influencia externa, por la expansión de la mancha urbana que ya ha alcanzado a varias de las subcomisarías y comisarías cercanas a Mérida y por la llegada de nuevos habitantes procedentes de la ciudad, de otras partes de la entidad y de fuera de ésta. En particular haremos mención a las corridas de toros organizadas en honor de los santos patrones de las comisarías de Komchén y San José Tzal. ${ }^{11}$ Cabe mencionar que estas festividades patronales son realizadas en la mayor parte de las 47 comisarías y subcomisarías de Mérida, incluso en aquellas que ya han sido alcanzadas por la mancha urbana como es el caso de Xcumpich, localizada al norte de la capital.

\footnotetext{
11 En ambas poblaciones se efectúan anualmente dos fiestas tradicionales, una en honor del santo patrono y otra dedicada a otra Virgen. En Komchén, la fiesta principal, en honor a san Isidro Labrador, se lleva a cabo en el mes de mayo y la segunda, en honor a la Virgen de Guadalupe, en diciembre. En San José Tzal la fiesta en honor al santo patrono, san José, se realiza en el mes de marzo y la segunda, en honor a la Virgen de la Concepción, en agosto.
} 
A fin de ejemplificar cómo el avance urbano ha impactado a las celebraciones tradicionales en las comisarías de Mérida y en la medida en que varias de ellas, tanto del norte como del sur, ya forman parte de la mancha urbana, presentamos el caso de Chuburná de Hidalgo, que de comisaría pasó a ser una colonia en la década de los setenta. Esta colonia meridana, como otras comisarías del municipio de Mérida, ha enfrentado ciertos problemas para la organización de sus fiestas patronales. Uno de ellos, sin lugar a dudas, está relacionado con la oposición de los nuevos vecinos por los estragos que las celebraciones generan, principalmente por el ruido y el cierre de calles para la instalación de puestos de comida y de otros productos, juegos mecánicos y el tablado ${ }^{12}$ donde se efectúan las corridas de toros. Igualmente, como parte de la infraestructura urbana, los espacios que antes se destinaban para la instalación del tablado, localizados frente a las iglesias, donde de manera tradicional se llevaban a cabo las fiestas para que el santo patrono pudiera observar desde el altar mayor, en la actualidad están ocupados por parques con bancas y juegos infantiles o canchas de usos múltiples. Por estas razones, en Chuburná, al igual que en algunas comisarías, como es el caso de Komchén y San José Tzal, el tablado es construido en un terreno, localizado a varias calles de la plaza principal, que fue elegido previamente por los mismos pobladores para la realización de esta festividad.

La organización de las fiestas patronales, que en años atrás recaía principalmente en una persona de reconocido prestigio o en un grupo de habitantes de las mismas comisarías que contaban con ciertos recursos económicos, en la actualidad puede estar en manos de empresarios foráneos, ya sea de otras poblaciones o de la ciudad de Mérida, que cuentan con capital para sufragar los gastos concernientes a la contratación de la orquesta que ameniza la vaquería, los conjuntos musicales para los bailes populares y el pago de los permisos correspondientes. Los organizadores, inclusive los empresarios foráneos, recurren a las empresas cerveceras que les proporcionan apoyo económico con la condición de que sus productos sean consumidos durante los días de las festividades.

Cuando los organizadores son personas de la misma población, como sucede en las dos comisarías de estudio, éstos eligen a un presidente, un secretario y un tesorero, quienes son los responsables de tramitar los permisos y de la contratación de los conjuntos musicales y de la charanga jaranera ${ }^{13}$ que amenizarán la

${ }^{12}$ Los tablados, generalmente de dos niveles, tienen una estructura hecha de palos que son atados con sogas de henequén o de nailon. El segundo piso tiene una cubierta de tablones donde se colocan sillas de plegar; también la gente acostumbra sentarse en la orilla de la baranda con los pies colgando hacia el ruedo. En el nivel superior, justo arriba de la puerta de acceso de los toros, se coloca la charanga jaranera que acostumbra acompañar a los toreros durante la lidia con conocidas jaranas y pasos dobles. Para acceder al nivel superior del tablado se utilizan rústicas escaleras construidas por los propios palqueros.

${ }^{13}$ Desde décadas atrás, la llamada plaza principal de Mérida es el lugar de reunión de los representantes de las charangas, de los grupos musicales y de las cuadrillas de toreros que actúan en las fiestas patronales en los pueblos de Yucatán. Los organizadores de las fiestas acuden a este lugar para realizar los contratos y el pago de los adelantos convenidos con los representantes o los propios músicos y toreros. 
vaquería, los bailes populares y las corridas de toros; y también a las cuadrillas de toreros que participarán en las corridas.

En subcomisarías del sur y del norte se observó que, por la precariedad de su economía, no había personas de las propias localidades o empresarios externos interesados en invertir para la organización de las fiestas por el temor de perder su capital. Se sabe que las familias no cuentan con los recursos para pagar la entrada a la vaquería, a los bailes populares, a las corridas de toros y para consumir los alimentos y bebidas que se venden durante los cuatro o cinco días que dura la festividad.

Los organizadores son los responsables de reunir los materiales necesarios para amarrar el tablado y realizar, cuando es necesario, la ceremonia de consagración del ruedo para que los dioses permitan la realización de las corridas sin ningún contratiempo. Esta ceremonia únicamente se lleva a cabo cuando los organizadores observan que en el terreno donde está construido el tablado se forman remolinos de viento, hecho que los primeros interpretan como una molestia de los dioses y para apaciguarlos proceden a enterrar en el centro del ruedo, junto al tronco que se utiliza para amarrar al primer toro de la tarde, un gallo y botellas de licor, además de ofrecer saká. Esta ceremonia la ejecutan por el temor que durante las corridas se formen remolinos que puedan ocasionar daños a la estructura del tablado, levantar los guanos, lonas y plásticos que se utilizan como techo y causarle daño a los espectadores. Según nuestros informantes, la consagración del tablado se ha realizado en San José Tzal más no así en Komchén, porque en esta última comisaría se han perdido mucho más las costumbres tradicionales.

Los palqueros, además de pedir a los dioses por la seguridad de la fiesta brava, también tienen que solicitar los permisos correspondientes a las autoridades municipales y estatales quienes se encargan de enviar a técnicos que verifican la estructura del tablado, la calidad de los materiales empleados en su construcción, incluyendo los que se utilizan para el techo: todo ello tiene como objetivo asegurar la integridad física de los espectadores. Se procura que los techos sean de materiales no inflamables, previniendo un incendio por efecto de las varas de los voladores. Otro elemento de reciente implantación en las corridas es la instalación de un corral de malla ciclónica, justo detrás de la reja por donde sacan a las reses del tablado, para evitar, como sucedía frecuentemente en años anteriores, que éstas se escapen y lesionen a las personas que permanecen en la calle y los alrededores. Igualmente, durante los festejos se cuenta con el apoyo de la Secretaría de Protección Civil para resguardar el orden y de una ambulancia lista para trasladar al hospital a quienes resulten heridos.

Los palqueros son un grupo de aproximadamente 40 personas que heredan de padres a hijos el derecho de ser los responsables de la construcción del tablado y forman parte del comité organizador de las festividades religiosas con el que se ponen de acuerdo sobre la contratación de los toreros y el monto del cobro de las entradas, entre otros aspectos. 
Se sabe que en algunas poblaciones hay empresarios que se responsabilizan de la organización total de la fiesta y de asumir todos los costos que ello implica, incluyendo la contratación de los grupos musicales, los permisos correspondientes, el alquiler del tablado y, por ende, el cobro de las entradas a todos los eventos.

En la construcción del tablado, los palqueros cuentan con el apoyo de los miembros de sus respectivas familias, incluyendo los niños y jóvenes, quienes se van socializando en esta actividad, e inclusive los más interesados aprenden de sus padres y abuelos la técnica para su edificación. Además, colaboran en el transporte y colocación de las sillas en el coso, del cobro de las entradas y de ubicar a los asistentes en sus respectivos asientos. Durante la fiesta taurina, cuyo precio de admisión varía entre 30 y 70 pesos, generalmente se lidian un buen número de reses, ${ }^{14} 20$ o más, con la particularidad de que sólo la primera es sacrificada para que inmediatamente se venda su carne entre el público asistente y el vecindario..$^{15}$

La corrida se inicia con la entrada al tablado de un grupo de hombres que se dirigen al centro del ruedo donde se encuentra un tronco, originalmente de ceiba, árbol sagrado de los mayas, pero en la actualidad sustituido por otros como el jabín o chulul, e inclusive postes de teléfono, y usado para atar al primer toro de la lidia. Estos individuos son los encargados de reventar voladores y una hilada o serie de petardos unidos entre sí que al prenderles fuego estallan uno inmediatamente después de otro. Esto tiene un doble significado: por un lado, anuncian a los pobladores que ya va a dar inicio la corrida y, por otro lado, la llegada del santo patrono transportado por un grupo de cargadores que, al compás de música de jarana, recorre de manera pausada toda la circunferencia del ruedo (figura 3). A la imagen se le despliega el manto para que los asistentes dejen caer sus ofrendas, generalmente monedas, que serán destinadas para las mejoras de la iglesia del pueblo. El santo patrono entra acompañado por el juez de plaza de la población, que puede ser el comisario municipal o ejidal, quien realiza el recorrido montado a caballo. Una vez concluido el paseo, es llevado de regreso a la iglesia y con ello se da inicio a la corrida de toros, la cual puede prolongarse por más de tres horas.

En los lapsos de tiempo en que los vaqueros entran al ruedo para sacar al toro que ya ha sido lidiado y mientras meten al siguiente animal, los vendedores bajan de las barandas del tablado para ofrecer al público su variada mercancía consistente en frutas de la época, dulces de algodón, merengues, paletas heladas, papas fritas, palomitas de maíz, chicles, refrescos embotellados y jugos na-

\footnotetext{
${ }^{14}$ En las corridas generalmente se lidian cebúes, la raza de ganado que se cría en los ranchos de los alrededores y también en los patios de las casas. En ocasiones se pueden torear uno o más toros de lidia.

${ }^{15}$ Es costumbre que con la carne se prepare el guiso llamado chocolomo que consiste en un caldo que incluye huesos, hígado, riñones, sesos y cinta; es aderezado con salpicón hecho de rábano, cilantro picado, sal y naranja agria.
} 


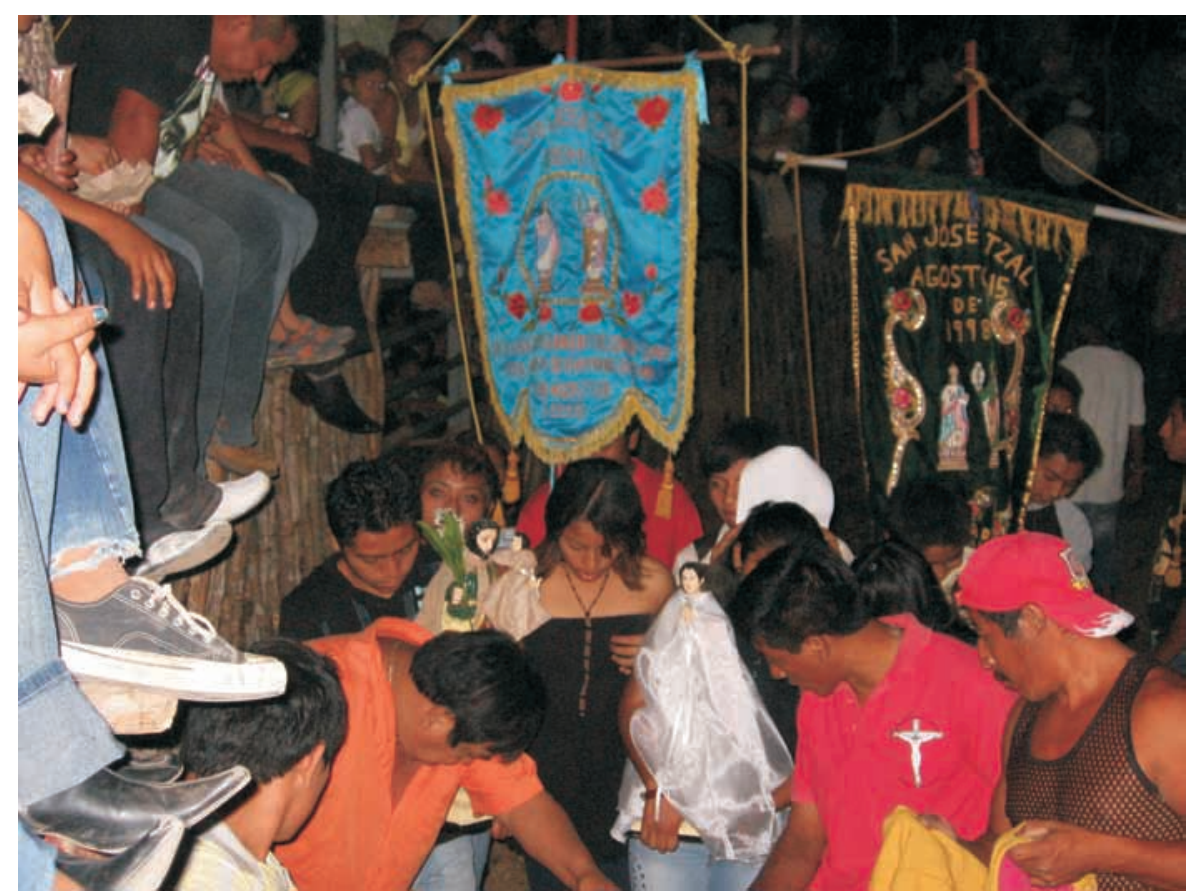

Figura 3. Entrada del santo patrono al tablado, acompañado de estandartes. Foto de los autores

turales, cigarros y otros muchos productos. Igualmente, a las afueras del tablado se instala una gran variedad de vendedores de alimentos: hamburguesas, tacos de carne asada, paletas heladas, churros, hot cakes, palomitas de maíz, chicharrones de harina y otros productos alimenticios; lo que extraña es que los antojitos regionales (panuchos, salbutes y tortas de pavo asado) están ausentes. Asimismo, se instalan puestos donde se ofrecen copias de discos y películas.

En las corridas, además de la cuadrilla de toreros que se encargan de la lidia (figura 4), participan más de 20 vaqueros, entre los que se encuentran jóvenes menores de 20 años y otros no mayores de 50, procedentes de las comisarías circunvecinas, de los pueblos pertenecientes a otros municipios e inclusive de la capital del estado. Ellos son los encargados de meter a los toros al ruedo para su lidia y posteriormente sacarlos y conducirlos a los camiones que los transportarán de regreso a sus lugares de origen. La participación de los vaqueros no representa una erogación para los palqueros, ya que ellos tienen en esta actividad un pasatiempo; de hecho, acuden a las fiestas patronales de los distintos pueblos de la entidad yucateca.

En lo que respecta a los toros que se lidian durante las corridas, muchas veces son dados en préstamo por ganaderos de la región o por criadores de traspatio como ofrenda al santo patrono en agradecimiento por la salud de un familiar o para que su ato se reproduzca y no enferme. De cualquier manera, los palqueros 


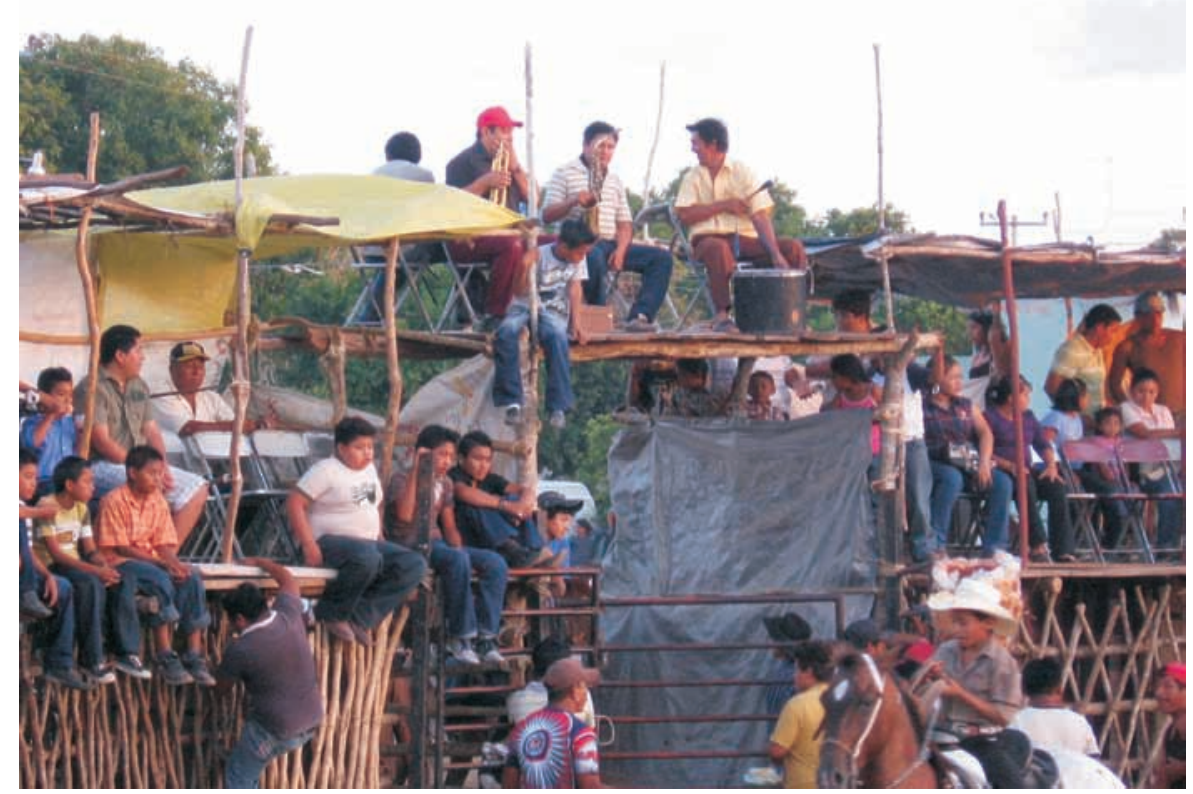

Figura 4. Vista del tablado durante la lidia del toro. Foto de los autores

acostumbran agradecer a estos ganaderos o a las personas encargadas de transportar a los animales de sus lugares de origen al tablado, con una bandeja de cuatro cervezas y alguna botana. En ocasiones, de acuerdo con la importancia de la plaza, los palqueros pueden alquilar toros de lidia, que ya han sido toreados en varias ocasiones, y a los que se les denomina matreros porque embisten más a los toreros y caballos que a los capotes, pagando por cada uno entre \$ 500 y \$ 700 .

Los organizadores de las fiestas, tanto en Komchén como en San José Tzal, han implementado estrategias para incrementar sus ganancias. Por un lado, realizan dos corridas más a la semana después de concluida la festividad tradicional, lo que se conoce como ochavario y, por otro lado, organizan charreadas o torneos de lazo. Esto se explica porque a decir de los entrevistados, los organizadores no siempre recuperan lo invertido en los cuatro o cinco días de la fiesta. Por ello se ven precisados a realizar al menos dos corridas más, generalmente el domingo y el lunes, aunque éstas ya no se consideran como parte de la fiesta del santo patrono sino más bien como un negocio que no contribuye a los fines y necesidades de la iglesia.

Un elemento que conviene destacar es que desde la década de los ochenta, cuando los pobladores de las comisarías se insertaron de manera informal al mercado de trabajo urbano (y contrariamente a lo que sucedía en décadas anteriores), es el hecho de que el horario de inicio de las corridas ha tenido 
que adecuarse a las nuevas condiciones impuestas por la estructura productiva como una estrategia que permite a los palqueros la posibilidad de recuperar la inversión hecha. Es decir, las corridas, sobre todo las que se realizan en los días hábiles, inician hasta las 5 o 6 de la tarde con el objetivo de que los trabajadores que laboran en Mérida o en otras poblaciones tengan el tiempo suficiente de llegar a sus casas y prepararse para el evento. Esto de igual manera permite que los habitantes de las comisarías circunvecinas interesados en asistir a las festividades se trasladen al lugar de la fiesta, para lo cual utilizan los medios de transporte colectivos como los camiones de pasajeros y los taxis o bien sus bicicletas o motocicletas.

\section{Consideraciones finales}

Con la crisis henequenera iniciada en la década de los setenta, la emigración pendular a la ciudad de Mérida, sobre todo a partir de 1980 debido a la oferta de trabajo creada por la industria de la construcción, se torna en una de las principales estrategias de los ejidatarios para la obtención de los recursos económicos que las labores en los planteles ya no les proporcionaba. Trabajar en la ciudad no sólo los obligó a interactuar con agentes externos, a comunicarse en español, a aprender diferentes oficios, sino también a observar y ser participes, hasta cierto punto, de nuevos elementos culturales como el uso de vestimenta occidental, el consumo de alimentos procesados, la compra de aparatos electrodomésticos, entre otros. No obstante, las comisarías meridanas, a pesar de su cercanía a la capital del estado, de la mayor dependencia de sus pobladores, hombres y mujeres, con respecto al mercado de trabajo y de la influencia de los medios masivos de comunicación, aún son espacios donde sus pobladores, por un lado, continúan reproduciendo algunos elementos culturales como las corridas de toros; mientras que otros, como las ceremonias agrícolas, están en franco proceso de abandono.

En el caso de las corridas de toros en honor de los santos patronos, se puede observar que los elementos culturales no desaparecen completamente sino que se adecuan a las nuevas características impuestas por la sociedad urbana. Al mismo tiempo se percibe que su práctica se está heredando, a través de la socialización, a las nuevas generaciones de jóvenes y niños que serán los responsables de continuarlas.

Algunas prácticas culturales son desarrolladas, se podría decir, sin la intervención ni la influencia de agentes externos a la comunidad. Tal es el caso del hetzmek, la consagración de los espacios de trabajo, la lengua maya, las ceremonias agrícolas, por mencionar algunas; mientras que en otros casos es innegable su presencia como en la organización de las fiestas patronales por parte de empresarios foráneos, y no siempre relacionados con la sociedad rural del municipio meridano. Igualmente, los organizadores se ven obligados a seguir las normas 
determinadas por las autoridades locales, municipales y estatales, y adecuar los festejos a los horarios de los trabajadores. El espacio tradicional donde se acostumbraba realizar las festividades taurinas, que había sido el entorno de la iglesia principal para que el santo patrono pudiera observar desde el altar, ha tenido que reubicarse como resultado del desarrollo de la infraestructura de las comisarías. Sin embargo, a pesar de ello, se siguen reproduciendo elementos culturales tradicionales como la edificación del tablado, la música de jarana, la quema de fuegos artificiales, la consagración del ruedo, entre otros.

En lo que concierne a las ceremonias agrícolas, se puede decir que las características culturales observadas en las comisarías de Mérida no son diferentes a las que se presentan en otros municipios de la ex zona henequenera. Allí, a pesar de la mayor distancia con respecto a la capital, su realización tradicional está cayendo en desuso aunque esto no significa que los milperos dejen de agradecer por los dones recibidos, sino que se están adecuando a las nuevas condiciones impuestas por la pérdida de importancia de esta actividad productiva, que se traduce en la palpable disminución de las extensiones cultivadas. En otras palabras, la realización de las ceremonias agrícolas tradicionales en los espacios dedicados a las milpas ha perdido importancia para ceder su lugar a las efectuadas en los altares domésticos y en las iglesias. Lo que sí ha cambiado es a quiénes van dirigidas: antes eran tanto para los dioses paganos como para los santos católicos, mientras que en la actualidad son principalmente para los segundos.

\section{BIBLIOGRAFÍA}

Cruz Rodríguez, María Soledad

2002 "Procesos urbanos y 'ruralidad' en la periferia de la zona metropolitana de la ciudad de México”, Estudios Demográficos y Urbanos, 1: 39-74. México: El Colegio de México.

Fernández Ruz, Alma Eva

2005 "Desarrollo económico y estrategias de sobrevivencia en dos subcomisarías de Mérida: Texán Cámara y Xcanatún”. Tesis de licenciatura en Ciencias Antropológicas, Mérida: Universidad Autónoma de Yucatán, Facultad de Ciencias Antropológicas.

Fernández Repetto, Francisco y Negroe Sierra, Genny

2006 Izamal festivo. Mérida: Instituto de Cultura de Yucatán / Universidad Autónoma de Yucatán.

Jardow-Pedersen, Max

1981 "El sacrificio de los toros. Comunicación musical y la corrida maya", Yucatán: Historia y Economía, 5 (25): 48-63. Mérida: Universidad Autónoma de Yucatán, Centro de Investigaciones Regionales, Departamento de Estudios Económicos y Sociales. 
Lugo Pérez, José A. y Tzuc Canché, Lizbet

2002 "Las ceremonias agrícolas y su paulatino abandono en Samahil, Yucatán”, Revista de la Universidad Autónoma de Yucatán, 16-17 (219-220), octubre-diciembre 2001/enero-marzo de 2002: 22-28. Mérida: Universidad Autónoma de Yucatán.

2006 "Las transformaciones de la estructura productiva en dos comisarías del municipio de Mérida", Perder el paraíso. Globalización, espacio urbano y empresariado en Mérida, pp. 95-115. L. A. Ramírez Carrillo (coord.). México: Miguel Ángel Porrúa/Universidad Autónoma de Yucatán (Serie Ciencias Sociales).

Lugo Pérez, José A.

2006 "Los movimientos migratorios en las comisarías y subcomisarías del municipio de Mérida", Perder el paraíso. Globalización, espacio urbano y empresariado en Mérida, pp. 69-94. L. A. Ramírez Carrillo (coord.). México: Miguel Ángel Porrúa/Universidad Autónoma de Yucatán (Serie Ciencias Sociales).

Tec Chan, Graciela

2005 "La lengua maya y sus transformaciones socioculturales en el marco de los procesos de desarrollo y modernización: el caso de una comisaría y subcomisaría: Chablekal y Texán Cámara”. Tesis de licenciatura en Ciencias Antropológicas, Mérida: Universidad Autónoma de Yucatán, Facultad de Ciencias Antropológicas.

Otras fuentes consultadas

Diario de Yucatán, sección Imagen, mayo 30 del 2009.

Padrón municipal de Mérida, 1992-1994, Archivo Municipal de Mérida, Yucatán. 